\title{
The use of new technologies in teaching ESP
}

\section{Nicole Chenik}

\section{(2) OpenEdition \\ Journals}

Electronic version

URL: http://journals.openedition.org/asp/4128

DOI: $10.4000 /$ asp.4128

ISSN: 2108-6354

Publisher

Groupe d'étude et de recherche en anglais de spécialité

\section{Printed version}

Date of publication: 1 July 1994

Number of pages: 1-16

ISSN: 1246-8185

\section{Electronic reference}

Nicole Chenik, "The use of new technologies in teaching ESP », ASp [Online], 4 | 1994, Online since 28 December 2013, connection on 20 April 2019. URL : http://journals.openedition.org/asp/4128 ; DOI : 10.4000/asp. 4128

This text was automatically generated on 20 April 2019.

Tous droits réservés 


\title{
The use of new technologies in teaching ESP
}

\author{
Nicole Chenik
}

1 For the past ten years, technology has been moving fast (Adams 1993). It has been moving so fast that new products become obsolete even more quickly than before or they are being continually transformed. As there is often a gap between what is available to the average teacher and what the researcher would like to design, this paper is in a way an attempt to keep up both as teacher and as researcher.

2 As a teacher I will start by looking at applications, with a brief critical review of what is available for ESP students. As a researcher, I will ponder over the implications of new technologies and try to provide guidelines, or rather express wishes, for future development.

\section{Applications}

\subsection{Available software at the time of writing (September 1993)}

Advances in computer technology, such as hypertext facilities, the ability to store increasingly large amounts of data -sound is notorious for being space-hungry- and the very recent digital video (Quicktime for Macintosh and Video for Windows for PCs), are attracting the attention of teachers because, for the first time, a reasonably satisfactory learning environment can be set up for students. This is a great improvement on traditional CALL programmes in that the new technologies bring together the elements considered necessary for successful language learning: sound, still pictures, video, and of course, text and text-based exercises.

4 The potential of these three technological advances, is enormous. With hypertext, units of text (usually a computer screen) can be linked up to others. The nodes are interconnected and each node contains several links to other nodes. The user must activate the available links to proceed to another node. The order in which the links are 
activated depends entirely on the user. This principle can be applied not only to text but also to other resources. As the capacity of computer platforms for multimedia have evolved, the capacity of these associative links has likewise been enlarged. The nodes can now be made up of sound, graphics, digitised still images or digitised full motion video sequences, all of which can be added as objects to be linked up whenever the author chooses to be accessed in whatever way the user decides. The problem of the addition of sound, one of the shortcomings of CALL, seems to be fading away now that sound can be saved directly on CD ROM, which avoids tedious manipulation of cassette recorders. Hypercard (with a colour version now) is not available on PC platforms, however, and PC hypertexts like Guide are widely recognized as less satisfactory.

5 Digital video is the latest step towards the integration of resources. Quicktime was launched in January 92 and is supplied with all new Macintosh machines. Video for Windows came out in January 93 in the US and in March 93 in France where it sells for less than FF1500 (Herellier 1993.) Few products, however, exist for the time being and there is scant research on the potential benefit of using hypertext for language learning since applications are just beginning to be developed. But it is possible to assess some of the ways in which hypermedia can make a valuable contribution to language learning.

Why is hypermedia particularly relevant to ESP? ESP students, of course, have special needs. They need to learn to communicate in the new language, and they need general and specialised vocabulary. They also need to be trained to be able to function in a business context, such as in the handling of the language of presentations, commenting on diagrams and charts, overhead transparencies, presenting software products, research results, reports and the like, or for instance, to be able to work in a business environment such as in a bank. For the most advanced, cross-cultural knowledge is not to be forgotten. Using video resources more widely can adequately provide concrete examples of situations, atmosphere, and an idea of corporate culture. They help students to decode a number of the signs connected to a particular culture.

7 It is quite clear that integration of the resources referred to above is relevant. Up to now, the software packages that were most adapted to ESP students, apart from the traditional CALL exercises, gap-filling or multiple choice, were essentially videodisks, such as the Connection series or the Aximedia products (commercially distributed by IIS [Interactive Information Systems] in Great-Britain). I will leave them aside, not because they are uninteresting, but because I have already commented on their potential elsewhere (Chenik 1994), and also because they are thought to be a dying technology. Aximedia in France has recently been taken over at a low price, and we might expect to find some bargains as prices drop and they sell off their stock. Informed sources agree that CD ROM will replace them at the leading edge of technology as CD ROM drives become cheaper. For language learning though, CD ROMs seldom offer interactivity and are too often the mere replica of older products. Two French products with digital video for ESP, Speak 92! and Speaker, are worthy of interest.

\section{Speak 92 !}

SPEAK 92! is devoted to English for Business in an American context. Two versions of the package exist, one on videodisk and another designed with Quicktime called the "lite version'. It offers ten to fifteen minutes of video on screen. Owing to compression techniques, the standard speed of images has been improved, from 15 per second under Quicktime to 20 per second with a Raster Ops card. This means better, if not excellent quality. It is mostly devoted to listening comprehension since it claims to offer 'linguistic 
immersion'. A series of questions are asked after the user has seen a video sequence. Comment is provided to help the user understand why his answers were wrong. In the 1.5 version, the user can also record his own voice and compare it with a native speaker model. No translation is available, although there is a help facility.

Depending on how each user answers, the content he is offered is adjusted by the knowledge base of the system. It takes individual progression into account and decides which unit to skip or which test should be tackled first. The teacher can monitor the system to assign a task to a user and decide on priorities. Student progress can, therefore, be monitored either by the system or by the teacher. The artificial intelligence-based system is called Smartsystem.

\section{Speaker}

Speaker has been on the market for two years as an authoring tool, but a new version is being developed on Windows, using Video for Windows. The whole package is easier to use than other well-known multimedia authoring systems such as Authorware Professional, and is aimed at teachers or resource centre organisers with little or no computer experience. It is quite flexible. Apart from the handling of text and text-based exercises, it can deal with:

11 Sound: It is possible to record a native speaker's voice, and then have students record and compare. Different types of graphs are available, either displaying a type of spectogram, or a bar chart indicating the stress in the sentence in visual form. There are other phonetics-based exercises which enable the user to listen to a sentence and then indicate on the screen in different colours where the stress is, whether there are elisions, where the weak form is, where sounds have to be linked. It can also be used in a more traditional form for listening comprehension with simple gap-filling exercises, accompanied by evaluation and correction.

Scanner: Scanning images takes a matter of seconds, and it is then possible to keep only part of the image if need be, or enlarge it with a zoom. Of course, images are relevant to any kind of language course, but this facility is especially useful for ESP since it enables the author to include technical documentation, illustrations, or graphs.

OCR: Optical Character Recognition is also available. Thanks to the toolbox facility, the user can choose any commercially available OCR system which best meets his needs.

Pictures from a camcorder are digitised instantly as well. This is useful for short scenes enacted by native speakers, or even for the students themselves to practise interviews, so that they are able to see instantly what is wrong with their performance and to rework it until they get the expected result.

As far as digital video is concerned, the choice has been not to try to make the picture as good as possible, but to accept the 15-image-per-second resolution so as to save space. It looks more like animated pictures than full motion video and is, of course, very far from videodisk quality. It is argued that, for the time being, this is a reasonable alternative in that it can be run on affordable machines. A better quality image would mean less space for practice and exercises and some users would not accept a limited number of exercises just to have a good picture. It also means that teachers can experiment with the contents and ponder over the reaction of the students when confronted with a multimedia environment and the learning process involved. 

is not yet available on Windows. It could cater for the short-term needs of a company, or resource centre, while more adapted units are being developed with the authoring tool. This is also one way of solving the old debate of the relative merits of dedicated versus authoring systems.

17 Hyperdocument: Only part of the work can be accessed in hypertext mode. The scanned image is divided into different zones and clicking on different parts of it triggers different reactions. The browsing or wandering is, however, quite limited since there is no hypertext facility as such for the text of the exercises. For the teacher, a summary of the lesson designed is available and, of course, everything can be changed and updated at will.

Speaker will be compatible with Quicktime for Windows as well. An interesting element is what is called the Toolbox, which includes OCR, a scanner and so on. In so far as the tools are independent of the rest of the package, they can be changed according to the user's needs and the evolution of the market. Paintbrush for instance can be replaced by something else.

\subsection{On-line retrieval of information}

Apart from commercially available software, the next element which is becoming increasingly popular is on-line retrieval of information. There has been abundant literature on the resources available for the humanities (from the CTI Centre for Textual Studies, for example), or for bibliographies. Little attention has been paid to ESP, whereas the potential here seems quite real. Large quantities of information are being compiled, as the publication of a database of databases testifies. In France, databases can be accessed for demonstration purposes or special queries at the British Council for British databases, or at the Cité des sciences et de l'industrie on different hosts. The most useful for ESP are DIALOG, and ESA (The European Space Agency). Costs vary depending on the server, the access mode, the telephone subscription costs, the type of network (national, European, international) and of course on the length of time it is used: 10 to 15 minutes on average, which costs about FF150 to FF250. A number of universities and research departments are connected to INTERNET, hence at least to DIALOG. I have chosen a few (see table 1).

Table 1

\begin{tabular}{|l|l|}
\hline Environment & ESA \\
ENVIROLINE & DIALOG \\
POLLUTION & \\
\hline $\begin{array}{l}\text { Computer Science } \\
\text { MICROCOMPUTER INDEX } \\
\text { TELEGEN-SUPERTECH (Software databases) }\end{array}$ & DIALOG \\
\hline
\end{tabular}




\begin{tabular}{|l|l|}
\hline Sciences / Techniques & ESA, DIALOG \\
CONFERENCES PAPER INDEX & DIALOG, GB \\
CURRENT TECHNOLOGY INDEX & DIALOG \\
\hline SCISEARCH & Information Science \\
INFORMATION SCIENCE ABSTRACTS & DIALOG \\
INSPECT INFOSCIENCE & ESA, GB \\
\hline BusineSS & DIALOG \\
INDINESS AND INDUSTRY NEWS DATA SOURCES & DIALOG \\
ICC (INTERCOMPANY COMPARISON) & DIALOG, GB \\
TEXTLINE & DIALOG, GB \\
\hline Management & DBI / INFORM \\
ECONOMIC LITERATURE INDEX \\
MAID
\end{tabular}

20 Company catalogues are of little pedagogic use as such, unless activities are organised, such as comparing the growth of small businesses in different countries or making forecasts from the data provided.

21 Summaries of research papers or articles, on the contrary, can prove very useful for advanced students. The students can download information for exposés or speeches. This was the case at Dauphine for two students presenting a paper on OCR and on neural networks. It proved to be extremely successful since they had access to the most up-todate information (which impressed their fellow students), and it was useful for their own research since they both worked in the field. They could even have sent summaries to other universities via the Internet network. This can lead to written activities, summarizing or expanding the information retrieved. The latter can provide written illustration of TV items, or documentaries (such as optical computing or telecommuting). There is here is an opportunity for exposure to different genres of writing and provides training in language and training in the retrieval of information. 
On-line resources are sometimes available on CD ROM, sometimes not. University libraries are likely to invest in CD ROM technology. For example, here is a list of what students have at their disposal in Paris IX Dauphine, and there are plans to acquire new titles. Some are in French, others in English (see Table 2).

Table 2

\begin{tabular}{|l|l|}
\hline DIANE & French Companies \\
\hline ABI/INFORM on Disc & American companies/economy/Management) (GB) \\
\hline LE MONDE EN CHIFFRES & Statistics/Le Monde \\
\hline KOMPASS & French Companies \\
\hline CHELEM & Statistics/International (GB) \\
\hline MACROECONOMIC DATA & World economy. Data from Eurostat, Bundesbank, IMF (GB) \\
\hline MEGASTAT FRANCE & Statistics from INSEE/Socioloy/Economy \\
\hline MEGASTAT CEE & Statistics/Europe \\
\hline BES & BILAN ECONOMIQUE ET SOCIAL Data from Le Monde (ed) \\
\hline LEXIS & Law \\
\hline MYRIADE & French journals and magazines and where to find them \\
\hline ELECTRE & French books \\
\hline
\end{tabular}

These then are the available applications. Teachers do have to teach with available means. It is obvious, however, that off-the-shelf products do not always meet the demands of language teachers, so I would now like to concentrate on the implications on a long-term basis.

\section{Implications}

\subsection{The structure of hypermedia}

Not many hypermedia products have been extensively tested. Articles, such as Slatin's (1990), or Kalaja's (1991) with the Hyperreader software for technical English, or Evan's Le Petit Nicolas (Evans, 1993), are mainly concerned with hypertext and the feedback from Le Petit Nicolas is from only seven users. So, before larger systems are designed, I deem it necessary to give some thought to the structure of hypermedia since the changes brought about by hypertext-mode exploration mostly deal with structure and the way knowledge is apprehended. The second point will focus on learner-centredness and the importance of standards and portability in the future. 

students are so accustomed to linear structure that they tend to use hypertext in linear form rather than exploit the non-linear structure, which after all seems quite normal since this is what we teachers have taught them to do! This may change with hypermedia since the very nature of the various nodes will be different, and a student will be able to choose whether he wants to start with text or audio material or video, with help facilities always just a click away. The help facilities themselves may vary from translation to definition, illustrations, complementary notes, grammar or access to a specialised database. As hypermedia makes different layers of knowledge available, it allows in-depth study of some aspects for some students, while others can choose to concentrate on other parts. It may in a way be able to bridge the gap between the traditional question 'do we teach communication skills or do we teach something which is content-based?' Some students could have access mostly to the material destined to improve communication skills, whereas more advanced students could explore the more specialised information contained in different nodes. Hypermedia encourages the creation of a learning environment that can be explored in many ways. The potential of hypermedia, theoretically, is clear. merely exploratory, how do we assess what has been learnt? If some tutorial mode is imposed, then some of the advantages of hypermedia are lost and it becomes a mere facilitator in the design of programmes, and the underlying philosophy of hypertext is lost.

Flexible solutions for structuring hypermedia should therefore be found, perhaps by suggesting different modes of access, such as:

- a guided tour, with a recommended pathway to follow, with a number of nodes that the learner is strongly recommended to visit, in which case it is advisable that the user be able to visualize a representation of the nodes and of the links.

- a semi-tutorial mode, where the designer keeps a hypertext-like presentation of the help facilities but within modules that have to be accessed in a pre-defined order, the ideal situation being that one hypermedia package could be accessed in different modes according to the user's wishes and needs.

31 It is quite obvious that, especially for ESP, the system should be able to cater for different levels of competence. If students are given the option of working on any part of the system, it may very well prove discouraging, being either too easy or too difficult, or if of the same level, de-motivating. For language practice, many teachers would agree that some graded progression is needed, even for rather advanced students (Stock 1992).

The system, therefore, should be adaptable to different levels, offering more in-depth study for advanced learners and more help facilities for the rest. It should also accommodate varied learning patterns. The non-sequential structure, however, will require careful design of the links and, most probably, the creation of some modules that can be accessed from any point (glossaries or translation aids) whereas others will have limited access (from only one card). This will work best if all objects in the system have been tagged. One could then imagine levels of glossary/grammar/exercise support varying dynamically as the learner's level becomes known to the system. 

hyperspace, which is the most commonly quoted danger of hypermedia, ideally, the student should also be able to insert new nodes with some comment of his own and to insert new links to associate existing links.

consider the exploratory type, this seems feasible. It has obviously been tried successfully by J. Slatin (1990) and it does seem relevant for the study of literature where the pooling of student impressions and research has proved extremely fruitful. It may not be so easy in the area of language learning, but one answer may be for students to create temporary files or cards which are later validated or not by the author. This would keep hypertext from becoming a maze of interconnected but tangled links.

\subsection{A learner-centred approach?}

Does this mean that the claims for a better learner-centred approach, thanks to multiand hypermedia, are lost? Learner-centredness and learner control have become buzzwords, and if we are to believe Ian Tudor, “...the essential feature of a learnercentred approach is that it caters for active participation by learners in the development of their study program." (Tudor 1992) The student should be given as much autonomy as possible. Of the necessary conditions mentioned by Tudor, I will quote three:

first two criteria apply quite well to ESP students, who are reasonably motivated, at least for English, because of career prospects and the fact that language courses are an opportunity to break away from a scientifically oriented curriculum. The third one is debatable since they tend to get discouraged easily, mainly because of a lack of clearly identifiable goals. In spite of that, we believe that most of them fit the requirements for at least partially autonomous learning reasonably well, provided that hypertext authors are ready to encourage autonomy and, at the same time, are aware that many learners need guidance and ask for it. If glossary, sound, images and text are included, it implies a larger degree of independence over what direction to take. Michael Evans clearly states:

Yet, this very degree of freedom can be seen as an obstacle to language acquisition as a degree of control may be necessary to ensure cumulative progression. Whilst at degree level foreign language learners would benefit from complete navigational control [...], at earlier levels, language learning requires a structure of support. For this reason, the relative value of hypertext or any other resource-based system needs to be checked against the needs of students at specific stages of language learning as well as against specific linguistic objectives. (Evans, 1993)

\section{So two aspects need to be preserved:}

- a "democratic" environment, where the learner can choose what best fits his learning style,

- necessary guidance when problems arise.

One possible approach would be to establish modules that could be accessed without any pre-defined order (on different themes, for instance), but whose content would be so structured that progression would be possible within the module. 

Technologies and at the same time hope that using them will reduce costs. Everyone remembers the first years of CALL when hardly anything was portable. Marketing initiatives such as Quicktime for Windows could help, since it offers the possibility of transferring Mac images to other PC platforms. MPC is the most commonly used though some do not find it powerful enough and some CD ROMs require special configurations. For photo quality still images, the accepted standard is JPEG (Joint Photographic Expert Group), which is a compression algorithm.

A new standard is being designed, MHEG (Multimedia Hypermedia Expert Group). It is supposed to be the specification of an international standard for the coding and presentation of multimedia objects, manipulated as autonomous units of information by the applications and exchanged within an application or between applications as well as 
on telecommunication networks. The aim is to obtain fully portable products. Hence the necessary definition of language objects that can be identified by the networks (Colaitis, Fromont, Leger 1993). It should be available in 1994. It has already been used experimentally by AFNOR, linking two workstations, one Mac and one PC WINDOWS via ISDN. Objects were exchanged without altering the presentation.

The future therefore seems to lie in the development of global communications as presented by G. Jacobs in his article in The CTISS File: "Without Wide Area Networking, multimedia in education is likely to remain at best an under-utilised resource and at worst an expensive toy." (Jacobs 1992.) The development of ISDN (Integrated Services Digital Network) -called RNIS and better known under the name NUMERIS in France- is under way and as the technology is here or almost, researchers should envisage the creation of multimedia product databases such as Staccato, ${ }^{1}$ which would foster computer to computer exchange. Of course this means that a number of legal aspects concerning copyright will have to be closely examined, such as the use of images, bits of video, news items, films once somebody wants to integrate them into a multimedia package, although visual libraries for multimedia excerpts may help as well as copyrights for the multimedia software that has been created.

\section{Conclusion}

I have not presented an invented-here-user-friendly or user-cuddly brand new discovery, but I think that anticipation of what is going to become available in a not too distant future and trying to see what can be done in the meantime is useful. For people at the sharp end of technology, this might be a little frustrating. Consolidation is sometimes as necessary as invention even if less exciting. Research is far from being unanimously uncritical about unrealistically high expectations concerning learning gains that might be impossible to sustain. So, in a way, language and CALL specialists - perhaps I should say TELL since Technology Enhanced Language Learning is gradually replacing the old acronym - now have, or almost have, the technology. If they want to be successful with it, they must concentrate on the structure of Hypermedia so as to be able to define a suitable, flexible architecture for the knowledge presented. Research into the organisation of contents and on how the new approach affects the learning process is needed if researchers want to avoid hypermedia turning into media hype. What is needed is a new approach to the way we design language courses to take advantage of the technology.

\section{BIBLIOGRAPHY}

Adams, John A. 1993. “Multimedia Special Report”. IEEE Spectrum March, 22-31.

Baird, P. 1989. Hypertext, Emancipation from Linear Slavery. Amsterdam: Electric Word.

Balpe, J.P. 1990. Hyperdocuments, Hypertextes, Hypermedias. Paris: Eyrolles. 
Bourcier, Patrice \& Pierre Antoine Taufor. 1993. La technologie multimédia. Paris: Hermès, Collection informatique.

Brochure du centre de Démonstration de l'édition électronique de produits d'information en ligne et sur CD ROM, British Council, Paris.

Burgess, Gordon J.A. 1991. “Hypertext CALL: A pragmatic approach”. ReCALL 5, 9-14.

Chenik, Nicole. 1994. "L'Hypertexte : quelles applications pour l'angliciste ? Quelle structuration?". Actes du colloque 1992, l'Informatique appliquée aux sciences humaines. Paris : Presses de l'Université Paris-Sorbonne.

Colaitis, Françoise, Joseph Fromont \& Alain Léger. 1993. “Technologie et outil de l' nseignement à distance : les standards multimédias". Journal de la Formation Continue et de l'EAO 269, 3-7.

Cole, Bernard. 1993. "The technology framework/special report multimedia”. IEEE Spectrum March, 32-39.

Darby, Jonathan (ed.). 1990. “Hypertext theme issue”. The CTISS File 9, Feb.

Darby, Jonathan (ed.). 1992. "Multimedia". The CTISS File 14, October.

Demaizière, Françoise \& Colette Dubuisson. 1992. De l'EAO aux NFT. Utiliser l'ordinateur pour la formation. Paris: Ophrys.

Evans, Michael. 1993. "NICOLAS: Using Hypercard with intermediate level French learners". System 2, 213-229.

Fouchard, Gilles, J.F. Raffestin \& Laurent Ohana. 1993. “Dossier multimédia”. Multimedia, juin 1993, 54-64.

Fox, Jeremy, Bev Labbett, Clive Matthew, Carmit Romano-Huid \& John Schostak. 1992. New Perspectives in Language Learning. Learning Methods Project Report. Employment Department/ University of East Anglia.

Fox Jeremy. 1992. "Some ideas about computer-based information systems". MUESLI Oct., 8-9.

Herellier, JM. 1993. “Quicktime or Video for Windows?”. Multimedia 6, mars 1993, 59-71.

Herellier, JM. 1993. Le Multimedia. Paris \& San Francisco: Sybex.

Jacobs, Gabriel. 1992. “An interactive revolution?”. The CTISS File 14, October, 3-5.

Jacobs, Gabriel. 1992. "Remote interactive multimedia: A necessary condition". The CTISS File 14, October, 12-15.

Kalaja, M., T. Lehtisalo, S. Hult \& O. Lassila. 1991. "Implementing an authoring tool for software: The HYPERREADER experience". ReCALL 5, Nov., 5-8.

Landlow, Georges P. 1992. Hypertext, The Convergence of Contemporary Critical Theory and Technology. Northampton: John Hopkins University Press.

Laufer, Roger \& Domenico Scaveta. 1992. Texte, hypertexte, hypermedia. Paris: Presses Universitaires de France.

Leffa, Wilson J. 1992. "Making foreign language texts comprehensible for beginners: An experiment with an electronic glossary". System 1, 63-74.

Liste thématique des Banques de données accessibles par la COMETE, Médiathèque de la Cité des Sciences et de l'Industrie, Paris. 
Meskill, Carla. 1991. "Language learning strategies advice: A study on the effects of on-line messaging”. System, 277-288.

Nielsen, Jakob. 1989. Hypertext and Hypermedia. San Diego, CA: Academic Press Inc.

Oxford, Rebecca, et al. 1993. 'Learning a language by satellite television: What influences student achievement". System 1, 31-48.

Semeteys, Alain. 1992. Le Multimedia. Paris: Dunot Technique.

Slatin, John M. 1990. “Text and Hypertext: Reflections on the role of the computer in teaching modern American poetry". In Miall, David S. (ed.), Humanities and the Computer. New Directions. Oxford: Clarendon Press, 123-136.

Stevens, Vance. 1991. "A study of student attitudes towards CALL in a self-access student resource centre". System, 289-300.

Stock, Roberta. 1992. "The potential impact of multimedia in language learning”. MUESLI October, 14-16.

Tarrasson, Jacques. 1992. Les outils du multimedia. Paris: Armand Colin.

Tudor, Ian. 1992. “Learner-centredness in language teaching: Finding the right balance”. System $1,31-44$.

Vieira, Luiz. 1993. "Vers l'intégration des systèmes tutoriaux intelligents dans les Hypermedias : une étude bibliographique". Journal de la Formation Continue et de l'EAO 269 avril, 11-14.

\section{NOTES}

1. For further information about Staccato, interested readers should contact Prof. David M. Bickerton, Director of the Centre for Modern Languages, University of Plymouth, Plymouth PL4 $8 \mathrm{AA}, \mathrm{UK}$.

\section{ABSTRACTS}

The latest technological developments have affected the design of software packages and the use that could be made of IT by learners. This has proven to be especially true for ESP because of the growing needs in the business world for vocational training, the increasing number of commercially available products, and the growing awareness that the specific needs of ESP students could best be met by the combination of text, image and sound resources. This paper starts with a brief critical review of available software. It then focuses on On-Line Retrieval of Information to assess how this can be of use to ESP. In outlining further developments, it stresses the need for standards and portability. It finally discusses hypertext and hypermedia structure and architecture to define conditions that would ensure greater facility of use and better learneroriented strategies.

La conception des logiciels a été influencée par l'évolution récente des techniques informatiques. C'est le cas dans le domaine de l'anglais de spécialité avec les besoins croissants de la formation 
continue, et la multiplication des logiciels disponibles dans le commerce, alors que l'on se rend compte que la combinaison du texte, du son et de l'image peut répondre aux besoins spécifiques des étudiants. Cet article présente quelques logiciels pour la langue de spécialité. Il évalue l'impact que peut avoir l'utilisation de ressources informatisées en ligne dans le domaine de spécialité. Les notions d'hypertexte, de structure et d'architecture des hypermédias sont examinées afin de définir des conditions qui permettraient d'envisager des stratégies orientées vers l'apprenant plus satisfaisantes. Établir des standards et une réelle portabilité donnerait des perspectives nouvelles.

INDEX

Mots-clés: anglais de spécialité, hypertexte, stratégie d'apprentissage, standard, vidéo Keywords: ESP, hypertext, learner-centred approach

\section{AUTHOR}

\section{NICOLE CHENIK}

Nicole Chenik enseigne à l'Université Paris 9 Dauphine. Nicole.Chenik@dauphine.fr 